\title{
(6) OPEN ACCESS \\ No association between abdominal pain and Dientamoeba in Dutch and Belgian children
}

\author{
Martijn Ramon Brands, ${ }^{1}$ Els Van de Vijver, ${ }^{2}$ Sjoukje Marije Haisma, ${ }^{1}$ Anke Heida, ${ }^{\oplus}$ \\ Patrick Ferry van Rheenen ${ }^{1}$
}

1Department of Paediatric Gastroenterology, University Medical Center Groningen, Groningen, The Netherlands ${ }^{2}$ Department of Paediatric Gastroenterology, Antwerp University Hospital, Edegem, Belgium

Correspondence to Dr Patrick Ferry van Rheenen Paediatric Gastroenterology, University Medical Center Groningen, Groningen 9700 RB, The Netherlands;

p.f.van.rheenen@umcg.nl

Received 12 October 2018 Revised 3 February 2019 Accepted 5 February 2019

\section{Check for updates}

(c) Author(s) (or their employer(s)) 2019. Re-use permitted under CC BY. Published by BMJ.

To cite: Brands MR, Van de Vijver E, Haisma SM, et al. Arch Dis Child Epub ahead of print: [please include Day Month Year]. doi:10.1136/ archdischild-2018-316383

\section{ABSTRACT \\ Objective To study the association between}

Dientamoebafragilis colonisation and faecal calprotectin to see whether the parasite is a harmless commensal or a gut pathogen.

Design Cross-sectional study of previously collected stool samples.

Setting and patients Two hundred stool samples originated from children aged 5-19 years with chronic abdominal pain and diarrhoea, who were seen in paediatric clinics in the Netherlands and Belgium and in whom somatic gastrointestinal disorders were excluded. Another 122 samples came from a healthy community-based reference population of the same age. All stool samples were analysed with real-time PCR for the detection of $D$. fragilis and with an ELISA for calprotectin - a biomarker of gastrointestinal inflammation.

Main outcome measures Prevalence of $D$. fragilis colonisation and results of stool calprotectin testing.

Results D. fragilis was detected in $45 \%(95 \% \mathrm{Cl}$ $38 \%$ to $51 \%$ ) of patients and in $71 \%(95 \% \mathrm{Cl} 63 \%$ to $79 \%$ ) of healthy children. Median (IQR) concentrations of calprotectin in patients and healthy children with a positive PCR result were not different from those with a negative PCR result (40 (40-55) $\mu \mathrm{g} / \mathrm{g}$ vs 40 (40-75) $\mu \mathrm{g} / \mathrm{g}$, respectively).

Conclusion since $D$. fragilis colonisation is most prevalent in healthy children and is not associated with an increase in faecal calprotectin concentration, our data do not support the inference that $D$. fragilis is a pathogenic parasite. Routinely testing for $D$. fragilis in children with chronic abdominal pain should therefore be discouraged.

\section{INTRODUCTION}

Dientamoeba fragilis, a flagellate protozoan parasite that inhabits the human bowel, was first described 100 years ago by Jepps and Dobell, who thought of it as a non-pathogenic organism. ${ }^{1}$ Since then, many studies have assessed the pathogenicity of $D$. fragilis in two indirect ways. First, by linking its presence to gastrointestinal symptoms, including diarrhoea and abdominal pain, and second, by observing whether eradication leads to resolution of symptoms. In table 1, we present an overview of the clinical studies that used these indirect methods from the year 2000 onwards. We show that, regardless of the method used, the controversy surrounding the pathogenicity of $D$. fragilis persists to this day.

A direct method to assess the pathogenicity of $D$. fragilis was used in mice, where inoculation with

\section{What is already known on this topic?}

- The debate about the pathogenicity of Dientamoeba fragilis is ongoing.

- Previous studies tried to link the detection of the parasite in stool to the presence of gastrointestinal symptoms or observed whether successful eradication led to resolution of symptoms.

- Faecal calprotectin is a sensitive marker of intestinal inflammation.

\section{What this study adds?}

We assessed whether the presence of $D$. fragilis in stool was associated with increased faecal calprotectin concentration.

- The lack of association between $D$. fragilis colonisation and intestinal inflammation suggests that the parasite is a harmless commensal.

- Routinely testing for $D$. fragilis in children with gastrointestinal symptoms should be discouraged.

D. fragilis induced an influx of eosinophils, neutrophils and macrophages in the intestinal wall. ${ }^{2}$ If a similar inflammatory response would take place in the human gut, it should be possible to measure an increase of calprotectin in stool of colonised patients. Calprotectin is a peptide mainly released by neutrophils and also by macrophages and monocytes invading the gut mucosa during an inflammatory response. ${ }^{3}$ To date, it has only been shown in a mouse model that $D$. fragilis is associated with an elevated faecal calprotectin concentration. ${ }^{4}$ In humans, this has not yet been investigated. We aimed to study the relationship between $D$. fragilis colonisation and stool calprotectin measurements.

\section{METHODS}

\section{Design}

This study was a retrospectively planned secondary analysis of prospectively collected data. We used stool samples from a community-based cohort of healthy children ('controls') aged 5-19 years ${ }^{5}$ and from children with chronic abdominal pain and diarrhoea ('cases') aged 6-18 years. ${ }^{6}$ 
Table 1 Studies on the pathogenicity of Dientamoeba fragilis. Excluding case studies and studies published before the year 2000

\begin{tabular}{|c|c|c|c|c|c|}
\hline \multirow[b]{2}{*}{ Study } & \multicolumn{2}{|l|}{ Research question } & \multicolumn{2}{|c|}{ Considers Dientamoeba to be } & \multirow[b]{2}{*}{ Detection methoc } \\
\hline & $\begin{array}{l}\text { Is the presence of GI symptoms } \\
\text { linked to positive stool tests? }\end{array}$ & $\begin{array}{l}\text { Does eradication lead to } \\
\text { resolution of symptoms? }\end{array}$ & Pathogenic & Not pathogenic & \\
\hline de Wit de et al ${ }^{17}$ & $\checkmark$ & & & $\checkmark$ & LM \\
\hline Bosman et al ${ }^{18}$ & & $\checkmark$ & $\checkmark$ & & TFT \\
\hline Stark et a ${ }^{19}$ & $\checkmark$ & & $\checkmark$ & & PCR \\
\hline Vandenberg et a $\left.\right|^{20}$ & & $\checkmark$ & $\checkmark$ & & PCR and TFT \\
\hline Kurt et $\left.a\right|^{21}$ & & $\checkmark$ & $\checkmark$ & & LM \\
\hline Stark et $a l^{22}$ & $\checkmark$ & $\checkmark$ & $\checkmark$ & & PCR \\
\hline Yakoob et $a^{23}$ & $\checkmark$ & & $\checkmark$ & & PCR and LM \\
\hline Engsbro et $a^{24}$ & & $\checkmark$ & & $\checkmark$ & $\mathrm{PCR}$ \\
\hline de Jong et $a^{12}$ & $\checkmark$ & $\checkmark$ & & $\checkmark$ & PCR \\
\hline Röser et al ${ }^{25}$ & & $\checkmark$ & & $\checkmark$ & PCR \\
\hline Bruijnesteijn van Coppenraet et a/ ${ }^{13}$ & $\checkmark$ & & & $\checkmark$ & PCR \\
\hline Krogsgaard et al ${ }^{11}$ & $\checkmark$ & & & $\checkmark$ & PCR and LM \\
\hline Ögren et $\left.a\right|^{26}$ & $\checkmark$ & & $\checkmark$ & & PCR and LM \\
\hline Holtman et al ${ }^{14}$ & $\checkmark$ & & & $\checkmark$ & PCR \\
\hline Jokelainen et $a l^{15}$ & $\checkmark$ & & & $\checkmark$ & PCR \\
\hline
\end{tabular}

$\mathrm{Gl}$, gastrointestinal; LM, light microscopy; TFT, triple faeces test.

\section{Setting and participants}

Controls $(n=122)$ were recruited from primary and secondary schools in the Netherlands between June 2015 and March 2016. Participants defecated onto a stool collection sheet (FecesCatcher, TAG Hemi VOF, Zeijen, The Netherlands) held above their toilet and collected one stool sample in a screw top container. In this way, contamination by toilet water was impossible. Containers were sent to the hospital laboratory of the University Medical Center Groningen. All samples with a transport time exceeding 7 days were excluded, as stability of calprotectin was no longer guaranteed. ${ }^{3}$ On arrival, samples were stored at $-80^{\circ} \mathrm{C}$ until further analysis. Detailed inclusion and exclusion criteria are listed in the published study protocol. ${ }^{5}$

Cases had persistent diarrhoea for more than 4 weeks, or more than two episodes of abdominal pain and diarrhoea in the past 6 months, and consulted a paediatrician for the first time for this complaint. They were recruited from 3 tertiary care and 16 secondary care centres in both the Netherlands and Belgium. ${ }^{6}$ Stool samples were collected between September 2014 and September 2016. The collection method, transport

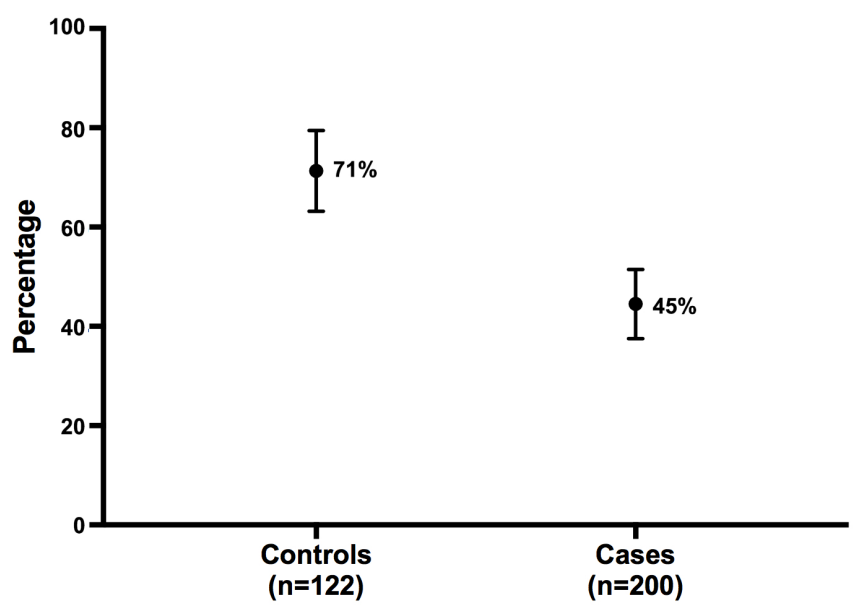

Figure 1 Point estimate (and 95\% Cl) of Dientamoeba fragilis prevalence in controls versus cases. time and storage were similar as described for the controls. For the purpose of this study, we excluded stool samples from cases who were eventually diagnosed with a somatic gastrointestinal disorder or gastrointestinal infection other than $D$. fragilis and remained with 200 stool samples for the current study.

\section{Measurements}

We used real-time PCR to determine the presence of $D$. fragilis. Additionally, faecal samples from cases were also tested for other gastrointestinal pathogens, including Shiga toxin-producing Escherichia coli, E. coli O157gen, Cryptosporidium, Entamoeba histolytica, Giardia lamblia, Salmonella, Shigella/enteroinvasive E. coli and Campylobacter. ${ }^{7}$ Calprotectin concentrations were measured with the fCal ELISA test of BÜHLMANN Laboratories AG (Schönenbuch, Switzerland).

\section{Variables}

Primary outcome of this study was the distribution of stool calprotectin concentrations in individuals colonised with $D$. fragilis compared with the distribution in those without the parasite.

\section{Statistical methods}

Demographic information and stool results were recorded electronically using SPSS V.22.0 for Windows and are presented with GraphPad Prism V.7 for Mac (GraphPad Software, San Diego, California, USA). Standard descriptive statistics were used. Not normally distributed variables are presented as median and IQR and were tested using the Mann-Whitney U test. All tests were two sided, and the level of significance was set at a $p$ value $<0.05$.

\section{Ethical approval}

The data were collected and recorded by the investigators in such a manner that subjects could not be identified, neither directly nor through identifiers linked to the subjects. The legal guardians from all participants, as well as the children aged 12 years and above, gave informed consent to use residual materials for future research. 


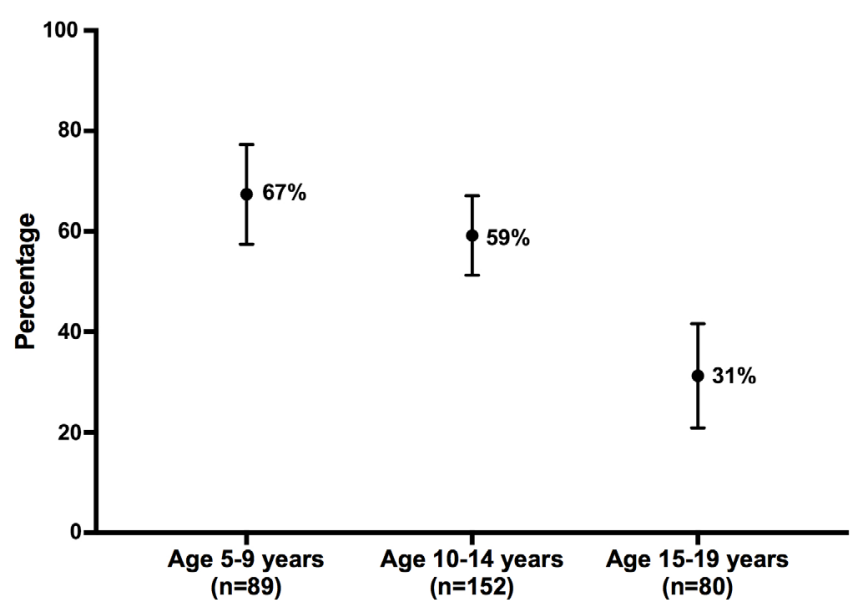

Figure 2 Point estimate (and 95\% Cl) of Dientamoeba fragilis prevalence per age category.

\section{RESULTS}

We analysed stool samples from 122 controls (48\% men) with a median (IQR) age of $12(9-14)$ years, and from 200 cases $(52 \%$ men) with a median (IQR) age of $12(9-15)$ years. Gender and age distribution were not different between groups $(\mathrm{p}=0.491$ and 0.154 , respectively).

\section{Prevalence}

Figure 1 shows that 87 of 122 controls (71\%, 95\% CI 63\% to $79 \%$ ) were colonised with $D$. fragilis, compared with 89 of 200 cases (45\%, 95\% CI 38\% to 51\%). The difference between groups was significant $(\mathrm{p}<0.001)$.

Figure 2 shows a decreasing prevalence of D. fragilis colonisation with increasing age during childhood and adolescence. When using 5 year intervals in age (5 to 9, 10 to 14 , and 15 to 19 years), D. fragilis prevalence was respectively $67 \%(95 \% \mathrm{CI}$ 57 to 76$), 59 \%(95 \%$ CI 51 to 67 ) and 31\% (95\%CI 22 to 42).

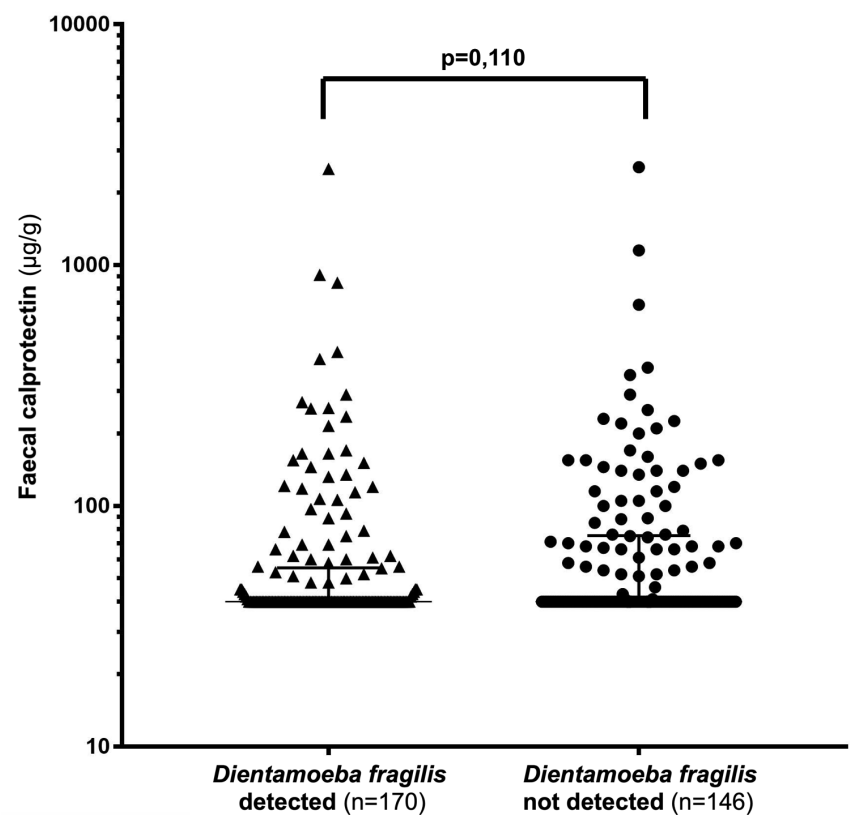

Figure 3 Dot plot of faecal calprotectin concentrations in children with and without Dientamoeba fragilis colonisation. The top whisker indicates the 75th percentile.
Faecal calprotectin

Six of 322 frozen samples contained too little faecal material to measure the calprotectin concentration. The remaining 316 samples were further analysed. One hundred and seventy samples (54\%, 95\% CI 48\% to 59\%) tested positive for D. fragilis. The median (IQR) calprotectin concentration in these samples was $40(40-55) \mu \mathrm{g} / \mathrm{g}$, compared with $40(40-75) \mu \mathrm{g} / \mathrm{g}$ in the $D$. fragilis-negative samples, as shown in figure 3.

\section{DISCUSSION}

In this paper, we present for the first time that D. fragilis colonisation in children and teenagers is not associated with increased faecal calprotectin concentrations. In combination with the observation that $D$. fragilis colonisation is most prevalent in healthy individuals, we postulate that the parasite is a non-pathogenic organism. Presence of the parasite does not trigger inflammatory cells to release calprotectin.

\section{Comparison with existing literature}

As far as we know, no other faecal markers of intestinal inflammation have yet been investigated on their association with $D$. fragilis. We identified one animal study that investigated the relationship between the presence of D. fragilis and faecal calprotectin in mice. ${ }^{4}$ The group of mice that were inoculated with $D$. fragilis had a mean (SD) faecal calprotectin concentration of 69 (22) ng/mL, compared with 33 (13) $\mathrm{ng} / \mathrm{mL}$ in control mice. The small sample size $(n=16)$ and the questionable applicability of this animal model to study human dientamoebiasis reduce the relevance of these observations.

Despite the use of the stool collection sheet to prevent the contamination of stool samples with toilet water, the prevalence of $D$. fragilis colonisation in the controls is among the highest currently reported. A literature search indicated that the prevalence of $D$. fragilis varied from $0.4 \%$ in healthy school children from Turkey ${ }^{8}$ to $61 \%$ in healthy school children from Lebanon. ${ }^{9}$ Higher prevalences can be partially ascribed to the use of realtime PCR, which is more sensitive than light microscopy. ${ }^{7}$ Furthermore, higher rates of $D$. fragilis colonisation are often seen where sanitation and hygiene levels are poor. ${ }^{10}$ Perhaps the high prevalence of $D$. fragilis colonisation is a reflection of the waning habit of hand washing before meals in the Netherlands.

The observation that $D$. fragilis is more commonly detected in healthy, non-symptomatic individuals than in symptomatic patients was previously done by numerous other adult and paediatric case-control studies. ${ }^{11-15}$ All of these studies questioned the pathogenicity of $D$. fragilis (see table 1 ).

\section{Implications for paediatric practice}

The availability of testing for $D$. fragilis, as part of the routine evaluation of children with gastrointestinal symptoms, varies between different European countries. We recently sent out a survey in the form of a clinical problem-solving exercise ${ }^{16}$ to assess the current practice in the Netherlands and Belgium in relation to $D$. fragilis. The 30 respondents came from paediatric centres involved in the recruitment of cases for the current study. We observed that there was no uniformity in the detection of $D$. fragilis nor in the management of $D$. fragilis positive children with chronic abdominal pain and diarrhoea. The approach varied from ignoring the presence of the parasite to making an effort to eradicate.

The findings of the current study add to the ongoing debate about the pathogenicity of $D$. fragilis. Detection of the parasite in stool is not associated with increased faecal calprotectin 
concentrations, and we therefore postulate that the parasite is merely a harmless commensal.

We acknowledge that stool calprotectin testing is an indirect method to evaluate neutrophil invasion of the gut mucosa. However, our observations that $D$. fragilis colonisation is: (1) not associated with increased faecal calprotectin concentrations and (2) most prevalent in healthy individuals do not justify invasive procedures such as taking mucosal biopsies to further investigate its pathogenicity. We advise against testing for $D$. fragilis in children with chronic abdominal pain.

Correction notice This article has been corrected since it first published online. The open access licence type has been amended.

Contributors PFvR conceived the study. AH, EVdV, SMH and PFvR initiated the study design. MRB drafted the first version of the article. All other authors revised the article critically for important intellectual content. All authors gave final approval of the version to be submitted.

Funding The authors have not declared a specific grant for this research from any funding agency in the public, commercial or not-for-profit sectors.

Disclaimer The company had no role in the design, execution, analyses and interpretation of the data, or in the decision to submit the results.

Competing interests PFvR received financial support from BÜHLMANN Laboratories AG (Schönenbuch, Switzerland) for other ongoing trials.

Ethics approval The Medical Ethics Review Committee of the University Medical Center Groningen confirmed that this retrospectively planned secondary analysis of two observational studies was not subject to the Dutch Medical Research Involving Human Subjects Act.

Provenance and peer review Not commissioned; externally peer reviewed.

Open access This is an open access article distributed in accordance with the Creative Commons Attribution 4.0 Unported (CC BY 4.0) license, which permits others to copy, redistribute, remix, transform and build upon this work for any purpose, provided the original work is properly cited, a link to the licence is given, and indication of whether changes were made. See: https://creativecommons.org/ licenses/by/4.0/.

\section{REFERENCES}

1 Jepps MW, Dobell C. Dientamoeba fragilis n. g., n. sp., a new intestinal amoeba from man. Parasitology 1918;10:352-67.

2 El-Gayar EK, Mokhtar AB, Hassan WA. Study of the pathogenic potential of Dientamoeba fragilis in experimentally infected mice. Parasite Epidemiol Control 2016;1:136-43.

3 Røseth AG, Fagerhol MK, Aadland E, et al. Assessment of the neutrophil dominating protein calprotectin in feces. A methodologic study. Scand J Gastroenterol 1992;27:793-8.

4 Munasinghe VS, Vella NG, Ellis JT, et al. Cyst formation and faecal-oral transmission of Dientamoeba fragilis--the missing link in the life cycle of an emerging pathogen. Int J Parasitol 2013:43:879-83.

5 Heida A, Kobold ACM, Wagenmakers L, et al. Reference values of fecal calgranulin C (S100A12) in school aged children and adolescents. Clin Chem Lab Med 2017;56:126-31.
6 Heida A, Van de Vijver E, Muller Kobold A, et al. Selecting children with suspected inflammatory bowel disease for endoscopy with the calgranulin $\mathrm{C}$ or calprotectin stool test: protocol of the CACATU study. BMJ Open 2017;7:e015636.

7 Bruijnesteijn van Coppenraet LE, Wallinga JA, Ruijs GJ, et al. Parasitological diagnosis combining an internally controlled real-time PCR assay for the detection of four protozoa in stool samples with a testing algorithm for microscopy. Clin Microbiol Infect 2009;15:869-74

8 Taş Cengiz Z, Akbayram S, Ciçek M, et al. Intestinal parasitoses detected in primary schoolchildren in the Van province]. Turkiye parazitolojii Derg 2009;33:289-93.

9 Osman M, El Safadi D, Cian A, et al. Prevalence and Risk Factors for Intestinal Protozoan Infections with Cryptosporidium, Giardia, Blastocystis and Dientamoeba among Schoolchildren in Tripoli, Lebanon. PLoS Negl Trop Dis 2016;10:1-18.

10 Stark D, Barratt J, Chan D, et al. the neglected trichomonad of the human bowel. Clin Microbiol Rev 2016;29:553-80.

11 Krogsgaard LR, Engsbro AL, Stensvold CR, et al. The prevalence of intestinal parasites is not greater among individuals with irritable bowel syndrome: a population-based case-control study. Clin Gastroenterol Hepatol 2015;13:507-13.

12 de Jong MJ, Korterink JJ, Benninga MA, et al. Dientamoeba fragilis and chronic abdominal pain in children: a case-control study. Arch Dis Child 2014;99:1109-13.

13 Bruijnesteijn van Coppenraet LE, Dullaert-de Boer M, Ruijs GJ, et al. Casecontrol comparison of bacterial and protozoan microorganisms associated with gastroenteritis: application of molecular detection. Clin Microbiol Infect 2015;21-592.e9-592.e19.

14 Holtman GA, Kranenberg JJ, Blanker MH, et al. Dientamoeba fragilis colonization is not associated with gastrointestinal symptoms in children at primary care level. Fam Pract 2017:34:25-9.

15 Jokelainen $\mathrm{P}$, Hebbelstrup Jensen $\mathrm{B}$, Andreassen BU, et al. Dientamoeba fragilis, a commensal in children in danish day care centers. J Clin Microbiol 2017:55:1707-13.

16 Dhaliwal G, Sharpe BA. Twelve tips for presenting a clinical problem solving exercise. Med Teach 2009:31:1056-9.

17 de Wit MA, Koopmans MP, Kortbeek LM, et al. Etiology of gastroenteritis in sentinel general practices in the netherlands. Clin Infect Dis 2001;33:280-8.

18 Bosman DK, Benninga MA, van de Berg P, et al. [Dientamoeba fragilis: possibly an important cause of persistent abdominal pain in children]. Ned Tijdschr Geneeskd 2004;148:575-9.

19 Stark D, Beebe N, Marriott D, et al. Prospective study of the prevalence, genotyping, and clinical relevance of Dientamoeba fragilis infections in an Australian population. $J$ Clin Microbiol 2005;43:2718-23

20 Vandenberg 0 , Peek R, Souayah $\mathrm{H}$, et al. Clinical and microbiological features of dientamoebiasis in patients suspected of suffering from a parasitic gastrointestinal illness: a comparison of Dientamoeba fragilis and Giardia lamblia infections. Int J Infect Dis 2006;10:255-61.

21 Kurt O, Girginkardeşler N, Balcioğlu IC, et al. A comparison of metronidazole and single-dose ornidazole for the treatment of dientamoebiasis. Clin Microbiol Infect 2008; 14:601-4.

22 Stark D, Barratt J, Roberts T, et al. A review of the clinical presentation of dientamoebiasis. Am J Trop Med Hyg 2010;82:614-9.

23 Yakoob J, Jafri W, Beg MA, et al. Blastocystis hominis and Dientamoeba fragilis in patients fulfilling irritable bowel syndrome criteria. Parasitol Res 2010;107:679-84.

24 Engsbro AL, Stensvold CR, Nielsen HV, et al. Treatment of Dientamoeba fragilis in patients with irritable bowel syndrome. Am J Trop Med Hyg 2012;87:1046-52.

25 Röser D, Simonsen J, Stensvold CR, et al. Metronidazole therapy for treating dientamoebiasis in children is not associated with better clinical outcomes: a randomized, double-blinded and placebo-controlled clinical trial. Clin Infect Dis 2014:58:1692-9.

26 Ögren J, Dienus O, Löfgren S, et al. Dientamoeba fragilis prevalence coincides with gastrointestinal symptoms in children less than 11 years old in Sweden. Eur J Clin Microbiol Infect Dis 2015;34:1995-8. 